\title{
Seed Chlorophyll Influences Vigor in Oilseed Rape (Brassica napus L. var $A C$ Excel.)
}

Joseph C. Onyilagha (Corresponding author)

Department of Biology, University of Arkansas at Pine Bluff

1200 North University Drive

Mail Slot 4972, AR 71601, USA

Tel: 870-575-8843 E-mail: onyilaghaj@uapb.edu

Bob H. Elliott

Agriculture and Agri-Food Canada

Saskatoon Research Centre, Saskatoon, Saskatchewan

Canada, S7N 0X2

Tel: 306-956-7274 E-mail: ElliottB@AGR.GC.CA

Edmund Buckner

Department of Agriculture, University of Arkansas at Pine Bluff

1200 North University Drive

Mail Slot 4913, AR 71601, USA

Tel: 870-575-5000 E-mail: bucknere@uapb.edu

Shadrach O. Okiror

Department of Agriculture, University of Arkansas at Pine Bluff

1200 North University Drive

Mail Slot 4913, AR 71601, USA

Tel: 870-575-8196_E-mail: okirors@uapb.edu

Phil J. Raney

Agriculture and Agri-Food Canada

Saskatoon Research Centre, Saskatoon, Saskatchewan

Canada. S7N 0X2

Tel: 306-956-7200 E-mail: raneyp@agr.gc.ca

Received: September 21, $2010 \quad$ Accepted: October 12, 2010 doi:10.5539/jas.v3n2p73

The research is financed in part by Agriculture and Agri-Food Canada Federal Matching Investment Initiative (MII)

\begin{abstract}
Seeds of Brassica napus L. var AC Excel were sorted into four subsamples on the basis of the amount of chlorophyll present. Vigor of the four subsamples was studied and compared using the germination test, accelerated aging test, controlled deterioration test and electrical conductivity test. Laboratory vigor ratings were correlated with field data. Results show that seed chlorophyll had no significant effect on germination. However,
\end{abstract}


seedling growth and performance were negatively affected by high chlorophyll. High chlorophyll subsamples were more sensitive to increased moisture and temperature than low chlorophyll subsamples. Additionally, seed conductivity study indicates that seed chlorophyll content is directly proportional to seed coat porosity. The usefulness of the four vigor test methods in assessing seed quality among chlorophyll seed lots of Brassica napus is also discussed.

Keywords: Brassica napus, Chlorophyll, Germination test, Seed vigor

\section{Introduction}

Brassica napus L. and B. rapa L. are commonly known as 'canola' or 'oilseed rape'. Brassica napus is the predominant oilseed species in Canada. The canola industry is large and ranks highly among other industries in the Canadian Prairies. The canola variety, AC Excel, is one of the early varieties developed at the Saskatoon Research Centre for its high oil content and seed yield. In recent times, intensive breeding programs have resulted in the emergence of several canola varieties which differ in oil profile and agronomic performance. $A C$ Excel still remains a reference check for the newly introduced varieties.

Canola seed is grown mainly for edible vegetable oil. The meal is used for the preparation of animal feeds. The presence of chlorophyll in seeds significantly reduces its market value, resulting in lower earnings to farmers and producers. Canola seed crushers downgrade seed lots with numerous green seeds (Ward et al., 1995). When seeds are crushed, the chlorophyll is extracted with oil, producing dark-coloured oil, which is aesthetically unappealing to consumers (Ward et al., 1995). Chlorophyll is a photosensitizer, promoting oxidation of oil in the light, leading to rancidity (Endo et al., 1984a, b; Usuki et al., 1984; Kiritsakis and Dugan 1985). Removal of chlorophyll from oil is by adsorption on bleaching clay, a process which is not only expensive, but may also lead to loss of oil to the bleaching clay (Mag, 1989).

Green seeds are usually formed as a result of high temperatures and drought stress during seed-filling (Prijic et al., 1998). Seed chlorophyll content may be low or absent when plants grow, and produce mature fruits under favorable environmental conditions. Jalink et al., (1998a) reported that the amount of chlorophyll in the seed coat decreases during maturation, a process known as 'degreening'. Seed-filling appears to be one of the most critical stages during seed development, as any adverse environmental stress during this process may result in seed chlorophyll accumulation and poor seed quality. Sanhewe and Ellis (1996a, 1996b) found that seeds of Phaseolus vulgaris L. harvested after the end of the seed-filling phase scored higher in a germination test, resulted in more normal seedlings and possessed better storability than seeds harvested at a less mature stage. In a similar study, Jalink et al., (1998b) reported that seeds of Brassica oleracea with the lowest amount of chlorophyll fluorescence had the highest percentage of germination and normal seedlings. Furthermore, they reported that crop management practices such as sowing rate, sowing date and swathing procedures influence the chlorophyll level of harvested seeds. The process of chlorophyll breakdown during seed maturation is not yet properly understood. Ward et al., (1995) reported that chlorophyll is broken down during the late stages of ripening and that the final chlorophyll level in rape seeds can be affected both by the genotype and the environment.

The need for high quality seed with strong vigor in B. napus has generated interest in the study of conditions and factors that influence these characteristics. However, there is limited information on factors which influence seed quality and vigor in canola. Elias and Copeland (1994) reported that storing canola seeds beyond ten months may result in significant drop of seed quality. There have been speculations as to whether seed chlorophyll affects germination and vigor in canola. Ward et al., $(1992,1995)$ studied the relation between the amount of chlorophyll and seed maturity in oilseed rape (Brassica napus L.) and turnip rape (Brassica rapa L.), but not much was said about the influence of chlorophyll on germination and vigor. In this study, we have employed the germination test, accelerated aging test, controlled deterioration test and conductivity test to assess the influence of seed chlorophyll on germination and vigor of B. napus. Because green seed canola is often not screened during seeding, the aim of our study was to determine whether accumulated chlorophyll has any direct effect on seed germination and vigor. Results of vigor tests will be correlated with field data, such as, number of seedlings per row, seedling fresh weight and biomass to determine whether there is any relationship between seed chlorophyll content and field agronomic performance.

\section{Materials and methods}

\subsection{Seed Material}

Four subsamples of seeds of Brassica napus var AC Excel with varying amounts of chlorophyll were selected for study. Actual amount of chlorophyll in each subsample was then analyzed spectrophotometrically in the 


\section{laboratory.}

\subsection{Spectrophotometric Determination of Seed Chlorophyll}

The procedure was a slight modification of American Oil Chemists' Society Official Method AK 2-92 (Mehlenbacher et al., 1992). Seed samples (1.5 gram) were placed in $20 \mathrm{ml}$ polyethylene terephthalate (PET) plastic scintillation vials (Wheaton No. 986741). To each vial was added a stainless steel rod measuring $8 \mathrm{~mm}$ by $25 \mathrm{~mm}$, followed by $15 \mathrm{ml}$ of extraction solvent (Heptane:Ethanol; 3:1 [vol : vol]). The vials were then capped, placed in a rack and shaken for $1 \mathrm{hr}$ on an Eberbach reciporating shaker ( 280 strokes/minute, $38 \mathrm{~mm}$ stroke) in a vertical direction. This thoroughly ground the seeds, and chlorophyll was extracted into the solvent. The vials were then centrifuged at $2500 \mathrm{rpm}$ for $15 \mathrm{~min}$ in a IEC Centra GP8 centrifuge equipped with a 216 rotor assembly to clarify the extracted solution. Absorbance of extracts was measured at wavelengths, 630, 665 and 700 using a Hewlett Packard 8453 spectrophotometer equipped with a sipper and a flow through cuvette $(1.0 \mathrm{~cm}$ path length, $3 \mathrm{~mm}$ aperture). The chlorophyll content of seed samples was then calculated as follows:

chlorophyll content, $\mathrm{mg} / \mathrm{kg}=\left(\mathrm{k} \times \mathrm{A}_{\text {corr }} \times \mathrm{V}\right) /(\mathrm{m} \times \mathrm{l})$

Where:

$$
\begin{aligned}
& \left.\mathrm{A}_{\text {corr }} \text { (the baseline corrected absorbance }\right)=\mathrm{A} 665-[(\mathrm{A} 700+\mathrm{A} 630) / 2] \\
& \mathrm{A} 665=\text { absorbance at } 665 \mathrm{~nm} \\
& \mathrm{~A} 700=\text { absorbance at } 700 \mathrm{~nm} \\
& \mathrm{~A} 630=\text { absorbance at } 630 \mathrm{~nm} \\
& \mathrm{k}=13 \text { (constant) } \\
& \mathrm{l}=\text { path length of the cuvette } \\
& \mathrm{m}=\text { mass of the seed sample, in grams } \\
& \mathrm{V}=\text { volume of extraction solvent. }
\end{aligned}
$$

\subsection{Germination Test (GT)}

Two hundred seeds were selected at random from each of the four subsamples. Seed moisture was standardized at $10 \%$. Each subsample was pre-incubated for $24 \mathrm{~h}$ at $20^{\circ} \mathrm{C}$ under $100 \% \mathrm{RH}$. Fifty seeds from each sub-sample were planted in a petri-dish ( $2 \mathrm{~cm}$ deep, $10 \mathrm{~cm}$ diameter) lined with a Whatman \# 4 filter paper. Each seed entry was replicated four times and laid out in the growth cabinet maintained at a constant temperature of $20^{\circ} \mathrm{C}, 50 \%$ $\mathrm{RH}, 16 \mathrm{~h}$ day light and $8 \mathrm{~h}$ darkness. First normal germination count was taken 4 days following incubation, and daily readings continued until day 7. Normal seedlings were harvested after day 7 , dried in an oven at $60^{\circ} \mathrm{C}$ for 6 days, and seedling dry weight was then measured.

\subsection{Accelerated Aging Test (AAT)}

Accelerated aging test was conducted using standard methods (Hamptom and Tekrony, 1995; Onyilagha et al, 2007). 200 seeds were taken randomly from each of the four subsamples and adjusted to $10 \%$ moisture level (Hamptom and Tekrony, 1995). Each sub-sample was placed on an accelerated aging tray obtained from Hoffman Manufacturing Inc., Albany, USA. The aging tray was inserted into an inner chamber containing $40 \mathrm{ml}$ of de-ionized water. Seeds were aged at $41^{\circ} \mathrm{C}$ for $24 \mathrm{~h}$ under $100 \% \mathrm{RH}$. At the end of the aging period, 50 seeds from each subsample were planted in a petri-dish $(2 \mathrm{~cm}$ deep, $10 \mathrm{~cm}$ diameter) lined with a Whatman \# 4 filter paper. Subsequent treatments followed same procedures as in the germination test above.

\subsection{Controlled Deterioration Test (CDT)}

200 seeds per subsample were adjusted to $20 \%$ moisture level (Hamptom and Tekrony, 1995), and immediately placed into an aluminum foil bag (laminated package composed of 12/20/50 micron polyester/aluminum foil/polythene). The bags were flattened with the edge of hand to remove air, and then heat sealed with a high power electric sealer (Hamptom and Tekrony, 1995; Onyilagha et al, 2007). The aluminum bags with seed were placed side down in a cabinet maintained at $10^{\circ} \mathrm{C}$ for $24 \mathrm{~h}$ for seed moisture equilibration. At the end of the equilibration period, entries were deteriorated in a chamber maintained at $45^{\circ} \mathrm{C}$ and $98 \pm 2 \% \mathrm{RH}$ for $24 \mathrm{~h}$. Seed samples were planted within one hour after deterioration (Hamptom and Tekrony, 1995) in a thermal-gradient plate. Fifty seeds from each subsample were planted in a petri-dish $(2 \mathrm{~cm}$ deep, $10 \mathrm{~cm}$ diameter $)$ lined with a Whatman \# 4 filter paper. Each seed entry was replicated four times. The plates were maintained at a constant temperature of $20^{\circ} \mathrm{C}$ and $98 \pm 2 \% \mathrm{RH}$, with $16 \mathrm{~h}$ day light and $8 \mathrm{~h}$ darkness. First normal germination count was taken 4 days following incubation, and daily readings continued until day 7. Normal seedlings were harvested 
after day 7 , dried in an oven at $60^{\circ} \mathrm{C}$ for 6 days, and seedling dry weight was then measured.

\subsection{Conductivity Test (CT)}

For CT, 200 seeds from each of the four subsamples were standardized at $10 \%$ moisture, followed by incubation for $24 \mathrm{~h}$ at $20^{\circ} \mathrm{C}$ under $100 \% \mathrm{RH}$. At the end of incubation period, seeds were immersed completely in $60 \mathrm{ml}$ de-ionized water. Conductivity was measured after $4 \mathrm{~h}, 8 \mathrm{~h}$ and $24 \mathrm{~h}$ periods. The instrument was a VWR 5005 model conductivity meter, equipped with a carbon conductivity cell, $\mathrm{K}=1.0$.

\section{Results}

Results of seed chlorophyll analysis, weight of 1000 seeds, germination test, accelerated aging test and controlled deterioration test are listed in Tables $1-3$. Result of statistical test on influence of aging temperatures and seed chlorophyll on germination and vigor is shown in Table 4. Seed performance was uniform among the subsamples in germination test (GT), irrespective of their varying amounts of chlorophyll. All subsamples achieved over $90 \%$ germination 7 days after planting. In the accelerated aging test (AAT) and controlled deterioration test (CDT), the subsample with least chlorophyll (6 ppm) gave higher germination than those with higher amounts of chlorophyll. Also, the subsample with the lowest chlorophyll level consistently achieved over $90 \%$ germination 7 days after planting in all tests. In the subsamples with high chlorophyll content, there was no observed pattern with respect to amount of seed chlorophyll and percent germination in the AAT and CDT. Table 4 shows that a combination of aging temperature and chlorophyll influenced germination of seeds in the AAT and CDT, while seed chlorophyll content had significant influence on conductivity. Result of seed conductivity test (CT) is shown in Table 2, and unlike in the AAT and CDT, there is a clearer pattern in the CT with respect to seed chlorophyll content and conductivity. Seed subsample with highest amount of chlorophyll $(60 \mathrm{ppm})$ consistently had highest conductivity, while subsample with least amount of chlorophyll (6 ppm) had least conductivity.

Table 3 shows the correlation between our laboratory vigor results and data obtained from field agronomic studies. Although many high correlation values were obtained, only few were statistically significant $(\mathrm{r} \geq 0.95$ at $5 \%$ probability level). The correlation pattern is such that germination counts in laboratory vigor tests taken 4 days after planting apparently had higher correlation with field data in the GT and AAT than counts taken 7 days after. Conversely, germination counts taken 7 days after planting in the CDT had higher correlation with field data than counts taken 4 days after. In the CT, conductivity increased with time (Table 2), however, correlation coefficients were inversely related with increased conductivity (Table 3 ).

\section{Discussion}

Result from the germination test suggests that under favorable environmental conditions, seed chlorophyll content may have no significant effect on germination of B. napus var AC Excel (Table1). However, in the event of any environmental stress, such as high temperature, as in CDT, and/ or moisture, as in AAT, germination of seeds of B. napus with high amounts of chlorophyll may be impaired (Tables 1 and 4). This is in agreement with Jalink et al., (1998b) who found in a controlled deterioration test, that seed subsamples of Brassica oleracea with lowest chlorophyll fluorescence signal had slightly lower germination and normal seedling percentages than the control seeds, whereas the seeds with highest chlorophyll fluorescence signals had much lower germination and lower normal seedling percentages. In another vigor study using the cold test,

Prijic et al., (1998) found that wrinkled soybean seeds gave better germination than chlorophyll seeds. They suggested that green seeds have non-functional tissues, and may be susceptible to fungal invasion.

Although chlorophyll had no significant effect on germination of subsamples in the germination test, however, its influence on dry weight of seedlings is highly significant (Table 4). Also, seedling dry weight appears to be related to seed weight, such that seeds with highest 1000-seed weight had highest seedling dry weight (Table 1). The result suggests that seed plants raised from large seeds accumulate higher biomass than those raised from small seeds. Similarly, seed plants raised from high chlorophyll seed lots may accumulate less biomass. In nature, accumulation of low biomass by seed plants may translate into low field performance. It is important to note that relation between our 1000-seed weight and chlorophyll content is apparently inverse, a finding which is in agreement with Jalink et al., (1998a), who also suggested that seed quality was inverse to the amount of chlorophyll in the seed coat.

In seed conductivity experiments, the amount of internal metabolites leached through the seed-coat is measured. Thus, it is also a measure of seed-coat integrity, whereby intact seed-coat resists excessive leaching of seed internal metabolites. The integrity of seed-coat is often related to seed vigor, and seed lots with porous seed-coat have high conductivity and low vigor. 
Results of our conductivity test (Table 2) show that increase in seed conductivity is directly proportional to seed chlorophyll, and inversely proportional to germination performance of seed subsamples (Table 1). Our results suggest that seeds with high chlorophyll content have higher porous seed-coat than the low chlorophyll subsamples. It is not certain whether high seed-coat porosity is related to seed maturity level. However, Ward et al., $(1992,1995)$ found a significant correlation between seed chlorophyll levels in harvested seed and time of maturity in eleven B. napus cultivars.

Correlation results (Table 3) show that germination test and conductivity test may be most suited for seed vigor evaluation among the chlorophyll samples. Data from the two tests had high correlation with field agronomic data, and significant correlation occurred with field data collected 21 days after planting. The inverse relation between high conductivity (Table 2) and correlation values (Table 3) supports our previous assertion that high conductivity is proportional to reduced field performance. Although germination results from AAT and CDT showed no significant correlation with field agronomic parameters, it is necessary to note that these two tests were stringent enough to predict the adverse effect of high seed chlorophyll on vigor, a characteristic which could not be discerned from the germination test (Table 4). The high correlation between seedling dry weight after seven days incubation and field agronomic data suggests that seedling dry weight may be a useful parameter for assessing vigor in chlorophyll seed lots.

\section{Summary}

Our findings may be summarized as follows:

a] Amount of seed chlorophyll (up to $60 \mathrm{ppm}$ ) may not have any significant effect on germination of $B$. napus seed lots, especially if they are planted during very low environmental stress conditions.

b] Seeds with high amount of chlorophyll are more prone to deteriorate in the presence of adverse environmental conditions than those with low chlorophyll.

c] High seed chlorophyll content negatively affects seedling vigor and overall field performance.

d] Seed-coat porosity is directly proportional to high seed chlorophyll.

e] High seed weight is proportional to biomass accumulation.

\section{Acknowledgments}

We are grateful to Sharon Leung, Mike Robinson and Larry Mann for their technical assistance.

\section{References}

Elias, S. G. \& Copeland, L. O. (1994). The effect of storage conditions on canola (Brassica napus L.) seed quality. Journal of Seed Technology, 18, 21 - 29.

Endo, Y., Usuki, R. \& Kaneda, T. (1984a). Prooxidant activities of chlorophylls and their decomposition products on the photoxidation of methyl linoleate. Journal of American Oil Chemist's Society, 61(4), 781 - 784.

Endo, Y., Usuki, R. \& Kaneda, T. (1984b). The photoxidative alteration of chlorophyll in methyl linoleate and prooxidant activity of their decomposition products. Agriculture and Biological Chemistry, 48(4), 985 - 989.

Hamptom, J. G. \& Tekrony, D. M. (1995). Handbook of Vigor test methods. Zurich, Switzerland, International Seed Testing Association (ISTA).

Jalink, H., Frandas, A., van Der Schoor, R. \& Bino, J. B. (1998a). Chlorophyll fluorescence of the testa of Brassica oleracea seeds as an indicator of seed maturity and seed quality. Scientia Agricola, 55, 88 - 93.

Jalink, H., van Der Scoor, R., Frandas, A. \& Van Pijlen, J. G. (1998b). Chlorophyll fluorescence of Brassica oleracea seeds as a non-destructive marker for seed maturity and seed performance. Seed Science Research, 8 , 437- 443.

Kiritsakis, A. \& Dugan, L. R. (1985). Studies in photoxidation of olive oil. Journal of American Oil Chemist's Society, 62(5), 892 - 896.

Mag, T. K. (1989). Bleaching - theory and practice. In D. R. Erickson (Ed.) Proceedings from the World Conference on Edible Fats and Oils Processing--Basic Principles and Modern Practices (pp 107 - 116) The Netherlands: Maastricht.

Mehlenbacher, V. C., Hopper, T. H., Smallee, E. M., Link, W. E., Walker, R. O. \& Walker, R. C. (1992). Official methods and recommended practices of the American Oil Chemist's Society. Champaign, IL: American Oil Chemist's Society. 
Onyilagha, J. C., Elliott, R. H, Olfert, O., Garner, J., Okiror, S. O. \& Katayama, R. (2007). Evaluation of seed quality and vigor in Canola, Brassica rapa L. In N. O. Tackie, R. Zabawa, N. Baharanyi, \& W. Hill (Eds.) Strategies to Influence the 2007 Farm Bill and Rural Policies: Impact on Diverse Cultures, Rural Communities and Underserved Farmers. (pp.137 - 146) Tuskegee, AL: Tuskegee University Press.

Prijic, L., Jovanovic, M. \& Glamoclija, D. (1998). Germination and vigor of wrinkled and greenish soybean seed. Seed Science \& Technology, 26, $377-383$.

Sanhewe, A. J. \& Ellis, R. H. (1996a). Seed development and maturation in Phaseolus vulgaris. 1. Ability to germinate and to tolerate desiccation. Journal of Experimental Botany, 47, 949 - 958.

Sanhewe, A. J. \& Ellis, R. H. (1996b). Seed development and maturation in Phaseolus vulgaris. II. Post-harvest longevity in air-dry storage. Journal of Experimental Botany, 47, 959 - 965.

Usuki, R., Endo, Y. \& Kaneda, T. (1984). Prooxidant activities of chlorophyll and pheophytins on the photoxidation of edible oils. Agriculture and Biological Chemistry, 48(4), 991 - 994.

Ward, K., Scarth, R., Daun, J. K. \& Vessey, J. K. (1995). Chlorophyll degradation in summer oilseed rape and summer turnip rape during seed ripening. Canadian Journal of Plant Science, 75, 413 - 420.

Ward, K., Scarth, R., Daun, J. K. \& McVetty, P. B. E. (1992). Effects of genotype and environment on seed chlorophyll degradation during ripening in four cultivars of oilseed rape (Brassica napus). Canadian Journal of Plant Science, 72, 643 - 649.

Table 1. Percent germination of seeds of Brassica napus var AC Excel with varying amounts of chlorophyll in a germination test (GT), accelerated aging test (AAT) and controlled deterioration test (CDT). Seed weight and dry weight of normal germinated seedlings are also shown

\begin{tabular}{|c|c|c|c|c|c|c|c|c|c|c|c|}
\hline \multirow{2}{*}{ Variety } & & \multicolumn{3}{|c|}{ GT } & \multicolumn{3}{c|}{ AAT } & \multicolumn{3}{c|}{ CDT } \\
\cline { 2 - 11 } & $\begin{array}{c}\text { Chlorophyll } \\
\text { content (ppm) }\end{array}$ & $\begin{array}{c}1000 \text { seed } \\
\text { wt. (g) }\end{array}$ & 4 days & 7 days & $\begin{array}{c}\text { Seedling } \\
\text { dry wt. (mg) }\end{array}$ & day 4 & day 7 & $\begin{array}{c}\text { Seedling } \\
\text { dry wt. (mg) }\end{array}$ & day 4 day 7 & $\begin{array}{c}\text { Seedling } \\
\text { dry wt. (mg) }\end{array}$ \\
\hline AC Excel & 6 & $2.7 \mathrm{~b}$ & $78.0 \mathrm{a}$ & $97.0 \mathrm{a}$ & $98.9 \mathrm{a}$ & $85.5 \mathrm{a}$ & $98.5 \mathrm{a}$ & $94.6 \mathrm{a}$ & $52.0 \mathrm{a}$ & $93.5 \mathrm{a}$ & $83.8 \mathrm{a}$ \\
\hline AC Excel & 15 & $3.2 \mathrm{a}$ & $74.5 \mathrm{a}$ & $90.5 \mathrm{a}$ & $99.8 \mathrm{a}$ & $70.5 \mathrm{ab}$ & $84.0 \mathrm{~b}$ & $94.5 \mathrm{a}$ & $25.5 \mathrm{~b}$ & $81.5 \mathrm{~b}$ & $85.6 \mathrm{a}$ \\
\hline AC Excel & 29 & $2.4 \mathrm{c}$ & $73.0 \mathrm{a}$ & $95.5 \mathrm{a}$ & $91.9 \mathrm{a}$ & $58.0 \mathrm{~b}$ & $90.5 \mathrm{ab}$ & $82.1 \mathrm{ab}$ & $6.5 \mathrm{c}$ & $56.0 \mathrm{c}$ & $46.6 \mathrm{~b}$ \\
\hline AC Excel & 60 & $2.1 \mathrm{~d}$ & $70.0 \mathrm{a}$ & $92.5 \mathrm{a}$ & $72.7 \mathrm{~b}$ & $62.5 \mathrm{~b}$ & $82.5 \mathrm{~b}$ & $68.1 \mathrm{~b}$ & $30.5 \mathrm{~b}$ & $71.0 \mathrm{~b}$ & $48.8 \mathrm{~b}$ \\
\hline
\end{tabular}

means within columns followed by the same letter are not significantly different (LSD, $\mathrm{p}=0.05$ ).

Table 2. Electrical conductivity measurements of seeds of B. napus with varying amounts of chlorophyll

\begin{tabular}{|c|c|c|c|c|}
\hline & \multirow{2}{*}{$\begin{array}{c}\text { Chlorophyll } \\
\text { Variety }\end{array}$} & \multicolumn{3}{|c|}{ Conductivity $(\mu \mathrm{S})$ over time $(\mathrm{h})$} \\
\cline { 3 - 5 } & content $(\mathrm{ppm})$ & $4 \mathrm{~h}$ & $8 \mathrm{~h}$ & $24 \mathrm{~h}$ \\
\hline AC Excel & 6 & $16.3 \mathrm{~d}$ & $26.7 \mathrm{c}$ & $47.5 \mathrm{c}$ \\
\hline AC Excel & 15 & $23.6 \mathrm{c}$ & $36.2 \mathrm{~b}$ & $65.1 \mathrm{~b}$ \\
\hline AC Excel & 29 & $28.2 \mathrm{~b}$ & $39.7 \mathrm{~b}$ & $67.7 \mathrm{~b}$ \\
\hline AC Excel & 60 & $36.9 \mathrm{a}$ & $49.2 \mathrm{a}$ & $86.3 \mathrm{a}$ \\
\hline
\end{tabular}

means within columns followed by the same letter are not significantly different (LSD, $p=0.05)$ 
Table 3. Pearson correlation between results of laboratory vigor tests and field agronomic data of B. napus var $A C$ Excel with varying amounts of chlorophyll in their seeds

\begin{tabular}{|c|c|c|c|c|c|c|}
\hline \multirow{2}{*}{$\begin{array}{c}\text { Type of test and time after } \\
\text { incubation }\end{array}$} & \multicolumn{2}{|c|}{ Seedlings / row } & \multicolumn{2}{|c|}{ Fresh weight } & \multicolumn{2}{|c|}{ Biomass } \\
\hline & 14 DAS & $21 \mathrm{DAS}$ & 14 DAS & $21 \mathrm{DAS}$ & 14 DAS & $21 \mathrm{DAS}$ \\
\hline \multicolumn{7}{|l|}{ Germination: } \\
\hline 4 days & 0.86 & 0.96 & 0.28 & 0.86 & 0.62 & 0.95 \\
\hline 7 days & 0.01 & 0.29 & -0.36 & -0.01 & -0.25 & 0.22 \\
\hline Seedling dry wt. & 0.91 & 0.82 & 0.73 & 0.92 & 0.90 & 0.86 \\
\hline \multicolumn{7}{|l|}{ Accelerated aging: } \\
\hline 4 days & 0.75 & 0.93 & -0.09 & 0.74 & 0.37 & 0.89 \\
\hline 7 days & 0.43 & 0.67 & -0.11 & 0.42 & 0.14 & 0.61 \\
\hline Seedling dry wt. & 0.97 & 0.91 & 0.65 & 0.98 & 0.90 & 0.94 \\
\hline \multicolumn{7}{|l|}{ Controlled deterioration: } \\
\hline 4 days & 0.44 & 0.68 & -0.46 & 0.43 & -0.00 & 0.62 \\
\hline 7 days & 0.73 & 0.85 & -0.09 & 0.72 & 0.37 & 0.83 \\
\hline Seedling dry wt. & 0.96 & 0.92 & 0.40 & 0.95 & 0.77 & 0.95 \\
\hline \multicolumn{7}{|l|}{ Conductivity: } \\
\hline 4 hours & -0.90 & -0.96 & -0.37 & -0.90 & -0.69 & -0.96 \\
\hline 8 hours & -0.86 & -0.95 & -0.32 & -0.86 & -0.63 & -0.94 \\
\hline 24 hours & -0.82 & -0.92 & -0.31 & -0.82 & -0.60 & -0.90 \\
\hline
\end{tabular}

$\mathrm{r} \geq 0.95$ significant at $5 \%$ probability level; DAS = days after seeding.

Table 4. Influence of aging temperatures and chlorophyll content on germination of seeds of Brassica napus var $A C$ Excel with varying amounts of chlorophyll in a germination test (GT), accelerated aging test (AAT) and controlled deterioration test (CDT). Influence of chlorophyll on conductivity (CT) is also shown

\begin{tabular}{|c|c|c|c|c|c|c|c|c|c|c|c|c|}
\hline \multirow{2}{*}{ Variables } & \multicolumn{4}{|c|}{ GT } & \multicolumn{4}{c|}{ AAT } & \multicolumn{3}{c|}{ CDT } & \multicolumn{2}{c|}{ CT } \\
\cline { 2 - 15 } & 4 days & 7 days & seedling dry wt. & 4 days & 7 days & seedling dry wt. & 4 days & 7 days & seedling dry wt. & $4 \mathrm{~h}$ & $8 \mathrm{~h}$ & $24 \mathrm{~h}$ \\
\hline Temperature & $\mathrm{ns}$ & $\mathrm{ns}$ & $\mathrm{ns}$ & $*$ & $\mathrm{~ns}$ & $\mathrm{~ns}$ & $* *$ & $* *$ & $\mathrm{~ns}$ & - & - & - \\
\hline Chlorophyll & $\mathrm{ns}$ & $\mathrm{ns}$ & $* * *$ & $* *$ & $* *$ & $* * *$ & $* * *$ & $* * *$ & $* * *$ & $* * * * * *$ & $* * *$ \\
\hline
\end{tabular}

$*$ at $\mathrm{p}=0.05 ; * *$ at $\mathrm{p}=0.01 ; * * *$ at $\mathrm{p}=0.001 ; \mathrm{ns}=$ not significant. 